\title{
Impact Of Domestic Violence On Conduct Disorder Among An Adolescents Sample
}

Ali Alkot ${ }^{1 \text {,* }}$ MD; Ali Alnabawy ${ }^{1}$ Ph.D; Mohamed $\operatorname{Ramadan}^{1}$ Ph.D; Adel Almadany ${ }^{1}$ Ph.D

*Corresponding Author:

Ali Alkot

\section{alkotnew@gmail.com}

Received for publication June 09, 2021; Accepted July 07, 2021; Published online August 23, 2021.

CopyrightThe Authors published by Al-Azhar University, Faculty of Medicine, Cairo, Egypt. Users have the right to read, download, copy, distribute, print, search, or link to the full texts of articles under the following conditions: Creative Commons AttributionShare Alike 4.0 International Public License (CC BY-SA 4.0).

doi: 10.21608/aimj.2021.78338.1487

${ }^{I}$ Psychiatry Department,Faculty of Medicine, Al-Azhar University, Cairo, Egypt.

\begin{abstract}
Background: Violence against children and adolescents represents a public health problem with serious compromises on physical and mental health, as well as for human development, Essential actions have to be taken to address this problem.

Aim of The Work: To test the hypothesis that domestic violence is contributed in presence of Conduct disorder in theEgyptian adolescents. Patient and Methods: The study was conducted on two samples. The first (the control sample) consisted of 50 adolescents from the admitted cases in the orthopedic department at Al-Hussein University Hospital and Sayed Galal University Hospital Cairo, Egypt. Their ages ranged from 12 to 18 years. They were subject to the conditions of inclusion in the sample.

And the second (cases) consists of 50 adolescents who suffer from conduct disorder according to DSM5 (Diagnostic and Statistical Manual of Mental Disorders 5th Edition) and Mini International Neuropsychiatric Interview (MINI) Kid.

Results: By conducting more statistical analyses on the questionnaire results, We note that there are statistically significant differences between the conduct disorder variable and the types of domestic violence (physical - verbal - social - economic - the threat of violence) for all members of the sample. The results showed statistically significant between the conduct disorder variable and the total degree of domestic violence among all sample members.

Conclusion: Adolescents are exposed to all typed domestic violence (physical, verbal, social, economic, the threat of violence), and there are statically significant results between the conduct disorder and domestic violence.
\end{abstract}

Keywords: Domestic violence; Conduct Disorder; Adolescents; Behavior.

Disclosure: The authors have no financial interest to declare in relation to the content of this article. The Article Processing Charge was paid for by the authors.

Authorship: All authors have a substantial contribution to the article.

\section{INTRODUCTION}

There are millions of children around the world living in aggressive and abusive homes; They suffer all kinds of physical and mental abuse that no child should face. ${ }^{1}$. It can be argued that children raised in violent homes believe that aggressive behavior is normal human behavior, so it is important to address this belief when it occurs among abused children. ${ }^{2}$

In the mid-1990s, the Adverse Childhood Experience Study indicated that children who were abused while experiencing domestic violence and aggressive forms of behavior were more likely to have physical and mental health problems. Exposure to chronic stress at an early age disrupts the balance in biological stress systems. ${ }^{3}$

In addition, child victims reported feeling more fearful, discouraged, and depressed than other children who had a safe home. In addition to internal disturbances, child victims also display more external behavior problems, such as aggressive and antisocial behaviours. $^{4}$
Additionally, children who are raised in abusive homes may be affected by a greater number of physical symptoms as well as other behavioral, psychological, and emotional despair. Children may experience general aches, such as headaches and stomach aches. They also experience symptoms such as irritable and irregular bowels, cold sores and may complain of nocturnal enuresis. ${ }^{5}$

Physical symptoms depressive disorders are a typical psychological consequence of domestic violence. In addition to general complaints of discomfort, children who witness domestic violence may also appear tense and may also experience symptoms of constant tiredness and fatigue. Additionally, schoolprone children may fall asleep due to lack of sleep at home, as most of the night can be spent watching violence in their homes. These children get sick frequently and have a lack of interest in personal hygiene; Children who are raised in abusive homes tend to participate in high-risk activities and develop suicidal tendencies. ${ }^{6}$ 
An established new fact is that child abuse and violence are also associated with psychosis and psychotic-like symptoms. In addition to the course of the disease, the meta-analysis shows that being victimized in childhood also predicts a worse course of depression, as measured by the number of exposures to such violence. Children who are most exposed to domestic violence are also more likely to have mental and behavioral disorders, and alcohol and drug dependence disorders. Experiments have also shown that children exposed to this type of abuse are at risk of relapse in the course of treatment for depressive disorders, and a lack of response to psychological treatment may appear. ${ }^{2,6}$

Violence may be a permanent part of human suffering, and its effects can be seen in various forms. Around the world, more than a million people lose their lives every year, and many more suffer from non-fatal injuries as a result of self-directed or interpersonal or group violence. On top of that, the death rate and violence-related diseases are responsible for 3\% of the burden of Global disease and ill health. ${ }^{78}$

The family is also considered the environment where the child acquires his social, religious and moral values. These values constitute the standards of his behaviour, ideas, habits and attitudes. The mission of the family is mainly based on carrying out the social upbringing that prepares the son to be a good citizen, and this family upbringing is summarized in the process of teaching children the language, morals, values and practices according to its cultural system, standards, and trends that are acceptable to itself and society. Behaviour. It can be discovered and can be modified according to the laws of learning. Therefore, behavioral research and studies in the study of violence focused on the fact that the entire behavior is learned from the environment, and then the various experiences from which the person acquired the aggressive behavior has been reinforced in a way that promotes the emergence of an aggressive response whenever he is exposed to the frustrated situation. ${ }^{9,10}$

Also, conduct disorders in children and adolescents are common in the general population (up to 5-10\% depending on the threshold). It leads to disability and often leads to antisocial behaviors and multiple mental and interpersonal health problems later in life.

In general, symptoms of conduct disorder develop in conjunction with high levels of environmental threat in the form of parental hostility, physical assault, marital discord and violence. This may be partly attributed to the interconnected risks between parent and child, but it is also likely to reflect a direct causal relationship.

Researchers studying parent-adolescent relationships are increasingly investigating the significance of parenting influencing adolescent development and how experiences in the family and other contexts interact with genetic factors to influence behavioral and developmental outcomes.

Adolescence is a transitional period from childhood to adulthood, with its onset by the maturation and compensation of puberty characterized by parents' independence. The paradox noted for human teens is that while they are stronger, faster, and more diseaseresistant, they have better reasoning and decisionmaking skills than children. ${ }^{11}$

Most mental health problems diagnosed in adulthood begin in adolescence. Half of the life-diagnosed mental health disorders begin at age 14; This number increases to three times at the age of 24 , and emotional and behavioral problems are noted in about $10-20 \%$ of children and adolescents. ${ }^{1}$

Longitudinal studies indicate that the proportion of young adults with the behavioral disorder in adolescents is much more significant than the proportion of young people who suffer from behavioral problems in childhood. Often these behavior problems can be a significant burden for the individual and a challenge, for example. School performance and well-being, or social relationships in the family, with friends and within the community. This study aims to identify the impact of domestic violence on Egyptian adolescents and its role in the occurrence of various behavioral disorders at this age stage. This study aimed to Explore association between Conduct disorder and domestic violence in sample of Egyptian adolescence

\section{PATIENTS AND METHODS}

\section{study design}

As an experimental study, a sample-oriented questionnaire was used to study according to the inclusion and exclusion criteria mentioned below. 100 adolescent participants participated in the study, they were divided into a control sample and an experimental sample with $50 \%$ each. The study was conducted between January 2017 and January 2018.

\section{The study sample}

The study was conducted on two samples, the first (the control sample) and 50 adolescents from the admitted cases in the orthopedic department at AlHussein University Hospital and Sayed Galal University Hospital Cairo, Egypt ages ranged from 12 to 18 years. They were subject to the conditions of inclusion in the sample.

And the second (cases) consists of 50 adolescents who suffer from conduct disorder according to the Diagnostic and Statistical Manual of Mental Disorders $5^{\text {th }}$ Edition (DSM5), which is the number of cases involved in the study of those attending psychiatric clinics at Al-Hussein University Hospital and Sayed Galal University Hospital Al-Azhar University, Cairo, Egypt.

\section{Inclusion criteria}

Participants of both sexes, ages 12-18, were included, adolescents and their parents agreed to participate in the research after clarifying its purpose.

\section{Exclusion criteria:}

Those with a previous history of chronic medical diseases or those with intellectual disability were excluded 


\section{Procedure:}

This study conducted in several steps: started with preliminary session for cases group with presence of their guardians to explain steps of the study and obtain their consent.

All cases were evaluated by semi-standard clinical interviews for adolescents who complain of symptoms of conduct disorder and determining the diagnosis of conduct disorder according to Diagnostic and Statistical Manual of Mental Disorders $5^{\text {th }}$ Edition (DSM5). Then the Family Violence Questionnaire after it is prepared by the research group, then whole results sent to statistical evaluation.

\section{Study tools}

Family Violence Questionnaire ( by Zeinab Shokair) was prepared as one of the study tools and conducting psychological tests on adolescents of both study groups after the consent of the teen's guardian while introducing them to how to answer the questionnaire and The Mini-international neuropsychiatric interview (M.I.N.I.) kid is a short structured clinical interview which enables researchers to make diagnoses of psychiatric disorders according to DSM-IV ( Diagnostic and Statistical Manual of Mental Disorders 4th Edition ), Arabic version (M.I.N.I) kid according to DSM 5 not available at time of this study. The Mini-international neuropsychiatric interview for adolescents who complain of symptoms of conduct disorder and determining the diagnosis of conduct disorder according to Diagnostic and Statistical Manual of Mental Disorders 4th Edition (DSM-IV). The researcher also conducted appropriate statistical treatments for the results that were reached through this study.

\section{RESULTS}

The studies sample were 100 (12-18 years old) with $35 \%$ of 12 years old than $20 \%$ of 17 years old, $75 \%$ of sample where male where about $28 \%$ where female, it was found that $74 \%$ of the sample members lived with parents. In comparison, $26 \%$ of them lived with the mother only (due to divorce, travel of the father, or the father's death), while there was no one among the sample members who lived with the father only or without the parents.

The study was conducted on males and females, and the proportion of males from the total sample was $72 \%$. It was the highest representation among the sample members. In comparison, the percentage of females was $28 \%$, according to the cases reported to Al-Hussein University Hospital and Sayed Jalal University Hospital under study.

Regarding living with parents, it was found that $74 \%$ of respondents live with parents. In comparison, $26 \%$ of them were living with the mother only (due to divorce, father travel or the death of the father), while none of the respondents lived with the father only or without the parents.

Regarding the number of children in the family, we found that adolescents in families with two children were the most represented among the total sample members at $41 \%$, with families with three children at $29 \%$, families with four children at $20 \%$ and families with children. The only child was $10 \%$. Most of the cases in which the first child in the family is $44 \%$ of the studied sample, $27 \%$ is a second child, $21 \%$ is a third child and $8 \%$ is a fourth child in the family

It was found that adolescents ranked first among their siblings and were the most represented among the members of the total sample by $44 \%$, followed by the second rank with $27 \%$, followed by the third rank with $21 \%$, followed by the fourth rank with $8 \%$.

This study represented the types of violence within the total sample Table (1) shows that low physical violence was the most representative among the total sample members by $42 \%$, followed by moderate and severe physical violence by $29 \%$ each, while low verbal violence was the most representative among the sample members by $35 \%$, followed by violence Acute verbal violence at $31 \%$, followed by moderate verbal violence at $30 \%$, followed by very severe verbal violence at $4 \%$. We find that moderate social violence at $43 \%$ was the most representative, followed by low social violence at $28 \%$, followed by acute social violence at $27 \%$, followed by very severe social violence at $2 \%$. We also find that moderate economic violence was the most representative among the members of the total sample at $43 \%$, followed by low economic violence at $33 \%$, followed by severe economic violence at $23 \%$, followed by very severe economic violence at $4 \%$. We find that the threat of moderate violence was the most representative among the total sample members at $34 \%$. The threat of violence, low at $33 \%$, followed by the threat of acute violence at $29 \%$, followed by the threat of very severe violence at $4 \%$.

\begin{tabular}{||c|c|c||}
\hline \multicolumn{2}{||c||}{ Conduct disorder s } & \multicolumn{1}{|c||}{} \\
\hline & $\mathrm{N}$ & $\%$ \\
\hline negative & $\mathbf{5 0}$ & $\mathbf{5 0}$ \\
\hline positive & $\mathbf{5 0}$ & $\mathbf{5 0}$ \\
\hline Total & $\mathbf{1 0 0}$ & $\mathbf{1 0 0}$ \\
\hline
\end{tabular}

Table 1: Adolescents with Conduct Disorder: The group of cases versus the control group in the sample

Table (2) shows that there are statistically significant differences between behavioral disorder and the male and female gender variable among the total sample members, as conduct disorder in male adolescents is higher than in females, and the results are statistically significant and can be interpreted. The result is that there are social norms, and this is consistent with some studies that have shown that the prevalence of conduct disorder in male adolescents is higher than in females by a rate that may reach in some studies the prevalence rate of 3 to 4 times in males than in females as in the study. 


\begin{tabular}{|c|c|c|c|c|c|c|c|}
\hline \multicolumn{2}{|r|}{ Degree } & \multicolumn{4}{|r|}{ Data } & & \\
\hline $\begin{array}{r}\text { Average } \pm \text { standard } \\
\text { deviation }\end{array}$ & Term & $\begin{array}{r}\text { Very } \\
\text { sharp }\end{array}$ & Sharp & Average & Low & & \\
\hline \multirow{2}{*}{$15.43 \pm 427.31$} & \multirow{2}{*}{ 58_3 } & $\mathbf{0}$ & 29 & 29 & 42 & Repetition & \multirow{2}{*}{ Physical violence } \\
\hline & & $0.00 \%$ & $29.00 \%$ & $29.00 \%$ & $42.00 \%$ & The ratio & \\
\hline \multirow{2}{*}{$18.426 \pm 29.38$} & \multirow{2}{*}{ 3_72 } & 4 & 31 & 30 & 35 & Repetition & \multirow{2}{*}{ Verbal violence } \\
\hline & & $4.00 \%$ & $31.00 \%$ & $30.00 \%$ & $35.00 \%$ & The ratio & \\
\hline \multirow{2}{*}{$9.636 \pm 18.36$} & \multirow{2}{*}{ 2_40 } & 2 & 27 & 43 & 28 & Repetition & \multirow{2}{*}{ Social violence } \\
\hline & & $2.00 \%$ & $27.00 \%$ & $43.00 \%$ & $28.00 \%$ & The ratio & \\
\hline \multirow{2}{*}{$9.276 \pm 14.82$} & \multirow{2}{*}{ _0-38 } & 4 & 23 & 40 & 33 & Repetition & \multirow{2}{*}{ Economic violence } \\
\hline & & $4.00 \%$ & $23.00 \%$ & $40.00 \%$ & $33.00 \%$ & The ratio & \\
\hline \multirow[t]{2}{*}{$14.750 \pm 22.33$} & \multirow[t]{2}{*}{ 2_51 } & 4 & 29 & 34 & 33 & Repetition & \multirow{2}{*}{$\begin{array}{r}\text { The threat of } \\
\text { violence }\end{array}$} \\
\hline & & $4.00 \%$ & $29.00 \%$ & $34.00 \%$ & $33.00 \%$ & The ratio & \\
\hline \multirow{2}{*}{$59.619 \pm 112.91$} & \multirow{2}{*}{$230 \_15$} & $\mathbf{0}$ & 29 & 40 & 31 & Repetition & \multirow{2}{*}{ Total } \\
\hline & & $\mathbf{0 . 0 0 \%}$ & $29.00 \%$ & $40.00 \%$ & $31.00 \%$ & The ratio & \\
\hline
\end{tabular}

Table 2: types of domestic violence among the sample members

By conducting more statistical analyses on the questionnaire results, we note that there are differences between the behavioural disorder and smoking variable, as a result, was statistically significant in adolescent smokers, as shown in Table 3.

\begin{tabular}{|c|c|c|c|c|c|c|c|c|}
\hline \multicolumn{5}{|c|}{ Conduct disorders } & \multirow{2}{*}{\multicolumn{2}{|c|}{ total }} & \multirow{2}{*}{\multicolumn{2}{|c|}{$\begin{array}{c}\text { Conformity } \\
\text { test }\end{array}$}} \\
\hline & \multicolumn{2}{|c|}{ negative } & \multicolumn{2}{|c|}{ positive } & & & & \\
\hline & $\begin{array}{c}\text { Repetitio } \\
n\end{array}$ & $\begin{array}{l}\text { The } \\
\text { ratio }\end{array}$ & $\begin{array}{c}\text { Repetitio } \\
n\end{array}$ & $\begin{array}{l}\text { The } \\
\text { ratio }\end{array}$ & $\begin{array}{c}\text { Repetitio } \\
n\end{array}$ & $\begin{array}{l}\text { The } \\
\text { ratio }\end{array}$ & Ca 2 & value \\
\hline Smoked & 2 & $4.00 \%$ & 15th & $30.00 \%$ & 17 & $17.00 \%$ & $\begin{array}{c}10.20 \\
6\end{array}$ & $\begin{array}{c}0.001 \\
4\end{array}$ \\
\hline $\begin{array}{c}\text { Non- } \\
\text { smoker }\end{array}$ & 48 & $96.00 \%$ & 35 & $70.00 \%$ & 83 & $83.00 \%$ & & \\
\hline Total & 50 & $\begin{array}{c}100.00 \\
\%\end{array}$ & 50 & $\begin{array}{c}100.00 \\
\%\end{array}$ & 100 & $\begin{array}{c}100.00 \\
\%\end{array}$ & & \\
\hline
\end{tabular}

Table 3: statistical relationship between smoking behaviour and conduct disorder

While studying the relationship between the behavioural variable and smoking among the sample

As shown in Table 4 that there were no statistically significant differences between the behavioural disorder variable and the age group over 15 years or less than 15 years between the total sample members. Besides, we also note that there are statistically significant differences between the conduct disorder variable and the types of violence (physical - verbal - social - economic - the threat of violence) for all individuals. (Table 5).

\begin{tabular}{|c|c|c|c|c|c|c|c|c|}
\hline \multirow{2}{*}{\multicolumn{2}{|c|}{ Conformity test }} & \multirow{2}{*}{\multicolumn{2}{|c|}{ Total }} & \multicolumn{4}{|c|}{ Behavior disorders } & \multirow{3}{*}{ Age } \\
\hline & & & & \multicolumn{2}{|c|}{ positive } & \multicolumn{2}{|c|}{ negative } & \\
\hline indication & Ca 2 & $\%$ & $\mathbf{N}$ & $\%$ & $\mathbf{N}$ & $\%$ & $\mathbf{N}$ & \\
\hline \multirow{3}{*}{0.317} & \multirow{3}{*}{1.002} & $51.0 \%$ & 51 & $46.0 \%$ & 23 & $56.0 \%$ & 28 & $<15$ \\
\hline & & $49.0 \%$ & 49 & $54.0 \%$ & 27 & $44.0 \%$ & 22 & $>15$ \\
\hline & & $100.0 \%$ & 100 & $100.0 \%$ & 50 & $100.0 \%$ & 50 & Total \\
\hline
\end{tabular}

Table 4: statistical relationship between the behavioral disorder variable and the age group 


\begin{tabular}{|c|c|c|}
\hline \multicolumn{2}{|c|}{ Age } & \multirow{2}{*}{ The link } \\
\cline { 1 - 2 } indication & $\mathbf{R}$ & $\begin{array}{c}\text { Physical } \\
\text { violence }\end{array}$ \\
\hline 0.412 & 0.083 & Verbal violence \\
\hline 0.805 & 0.025 & Social violence \\
\hline 0.332 & 0.098 & $\begin{array}{c}\text { Economic } \\
\text { violence }\end{array}$ \\
\hline $0.046^{*}$ & 0.200 & $\begin{array}{c}\text { The threat of } \\
\text { violence }\end{array}$ \\
\hline 0.106 & 0.162 & Total \\
\hline 0.225 & 0.122 & \\
\hline
\end{tabular}

Table 5: statistical relationship between types of violence and age

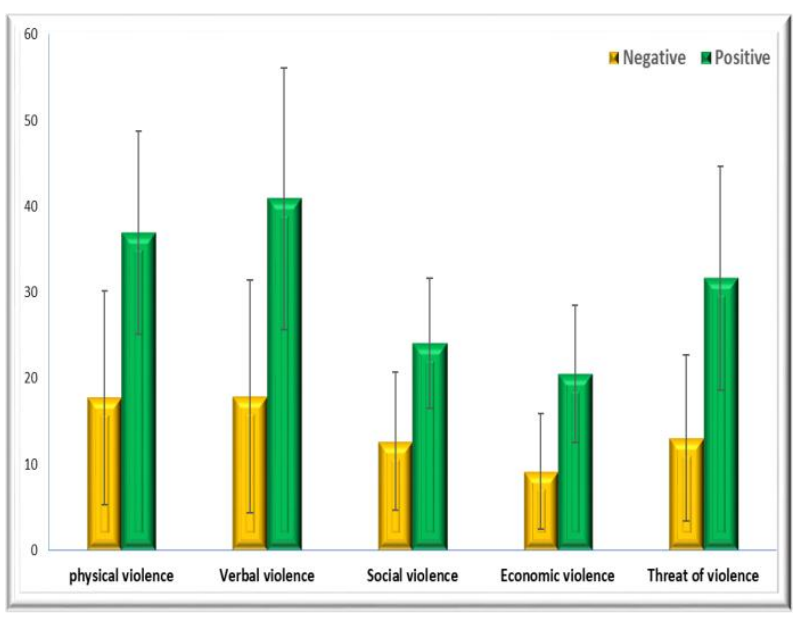

Fig. 1: Examine the relationship between the variable of Conduct disorders and domestic violence.

From the above, the study showed the relationship between the conduct disorder variable and domestic violence; we note that there are statistically significant differences between the conduct disorder variable and the types of violence (physical - verbal social - economic - the threat of violence) for all the sample members. Hence, the results showed statistical significance between the variable. Conduct disorder and the overall degree of domestic violence among all members of the sample

\section{DISCUSSION}

The study found that males have a higher degree of impulsive behaviour than females, meaning that males are more impulsive, and the results are statistically significant.

This result can be explained by the fact that some societies tend to accept impulsivity, excessive movement, and some behaviors from males. In contrast, they do not accept females, as the girl should be quiet, shy, and need care and protection. Some behaviors are rejected and not socially acceptable to girls compared to boys, such as physical violence and fights.

While the results differ from that, conduct disorder in females is higher than in males, especially in some behaviors such as theft, running away from home, and sexual relations. The study's author advises that the variation in the prevalence rates between males and females in conduct disorder needs more research and understanding. The researcher believes that the difference in the assessment of Rates of conduct disorder may be due to the approved diagnostic method, the age group in which the research was conducted, or the communities and cultures in which the research was conducted. The current study shows that aggressive behavior at home may bring about various social issues for young men and young ladies. The CBCL absolute score and subscale scores of uneasiness/discouragement, social cooperation issues, consideration issues, misconduct, hostility, and externalizing practices of young men presented to aggressive behavior at home were altogether higher than those of the benchmark group. However, the distinctions of the entirety of the CBCL scores in young ladies between the two gatherings were not critical. This demonstrates that the young men presented with aggressive behavior at home would, in general, experience the ill effects of more mental and conduct problems. Domestic viciousness forced an unfavorable impact on conduct in children and adolescents.

\section{CONCLUSION}

Researchers studying parent-adolescent relationships are increasingly investigating the significance of parenting influencing adolescent development and how experiences in the family and other contexts interact with genetic factors to influence behavioral and developmental outcomes.

Adolescence is a transitional period from childhood to adulthood, with its onset by the maturation and compensation of puberty characterized by parents' independence. The paradox noted for human teens is that while they are stronger, faster, and more diseaseresistant, they have better reasoning and decisionmaking skills than children.

The study was conducted on two samples. The first (the control sample) consisted of 50 adolescents from the reserved cases in the orthopedic department at Al-Hussein University Hospital and Sayed Galal University Hospital Cairo, Egypt, and their ages ranged from 12 to 18 years. They were subject to the conditions of inclusion in the sample.

And the second (cases) consists of 50 adolescents who suffer from Conduct disorder according to the Diagnostic and Statistical Manual of Mental Disorders 5th Edition (DSM5.(

The low physical violence was the most represented among the total sample members by $42 \%$, followed by moderate and severe physical violence by $29 \%$ each, while low verbal violence was the most represented among the sample members at 35\%, followed by severe verbal violence by $31 \%$, followed by moderate verbal violence by $30 \%$, followed by verbal violence. Very severe, at $4 \%$, and we find that moderate social violence, at $43 \%$, was the most representative, followed by low social violence, at $28 \%$, followed by acute social violence, at $27 \%$.

From the abovementioned, the investigation showed the connection between the social problem variable and aggress behavior we note that there are measurably huge contrasts between the conduct issue 
variable and the sorts of viciousness such as physical, verbal, social, financial and danger of savagery for all the example individuals. Thus, the outcomes showed measurably critical between the variable. Direct confusion and the general level of aggressive behavior at home among all individuals from the study population.

\section{REFERENCES}

1. S Pisano, P Muratori, Ch Gorga, V Levantini, R Iuliano, G Catone, et al., "Conduct disorders and psychopathy in children and adolescents: etiology, clinical presentation and treatment strategies of callous-unemotional traits," Italian journal of pediatrics, 2017;43(1)1-11.

2. Bakker-Huvenaars, M. J., Greven, C. U., Herpers, P., etal . Saliva oxytocin, cortisol, and testosterone levels in adolescent boys with autism spectrum disorder, oppositional defiant disorder/conduct disorder and typically developing individuals. European Neuropsychopharmacology, 2020, 30, 87-101.

3. Fanti, K. A., Kyranides, M. N., Lordos, A., Colins, O. F., \& Andershed, H. . Unique and interactive associations of callous-unemotional traits, impulsivity and grandiosity with child and adolescent conduct disorder symptoms. Journal of Psychopathology and Behavioral Assessment, 2018 , 40(1), 40-9.

4. Balia, C., Carucci, S., Coghill, D., \& Zuddas, A. The pharmacological treatment of aggression in children and adolescents with conduct disorder. Do callousunemotional traits modulate the efficacy of medication?. Neuroscience \& Biobehavioral Reviews, 2018, 91, 218-38.

5. DeLisi, M., Drury, A. J., \& Elbert, M. J. The etiology of antisocial personality disorder: The differential roles of adverse childhood experiences and childhood psychopathology. Comprehensive psychiatry, 2019, $92,1-6$.

6. MKyranides, M. N., Fanti, K. A., Katsimicha, E., etal - Preventing conduct disorder and callous unemotional traits: preliminary results of a school based pilot training program. Journal of abnormal child psychology, 2018, 46(2), 291-303.

7. Sigurvinsdottir, R., Asgeirsdottir, B. B., Ullman, S. E., \& Sigfusdottir, I. D. . The impact of sexual abuse, family violence/conflict, spirituality, and religion on anger and depressed mood among adolescents. Journal of interpersonal violence,2021,36(1-2), 577-97.

8. Ibabe, I. . Adolescent-to-parent violence and family environment: The perceptions of same reality?. International journal of environmental research and public health, 2019, 16(12),15-22.

9. Ngo, Q. M., Veliz, P. T., Kusunoki, Y., etal . Adolescent sexual violence: Prevalence, adolescent risks, and violence characteristics. Preventive medicine, 2018, 116, 68-74

10. Calvete, E., Gámez-Guadix, M., FernándezGonzalez, L., etal .Maladaptive schemas as mediators of the relationship between previous victimizations in the family and dating violence victimization in adolescents. Child abuse \& neglect, 2018, 81, 161-9.

11. Urben, S., Habersaat, S., Pihet, S., etal . Specific contributions of age of onset, callous-unemotional traits and impulsivity to reactive and proactive aggression in youths with conduct disorders. Psychiatric quarterly, 2018, 89(1), 1-10. 